\title{
N-terminal acetylation promotes synaptonemal complex assembly in C. elegans
}

\author{
Jinmin Gao, ${ }^{1}$ Consuelo Barroso, ${ }^{2}$ Pan Zhang, ${ }^{3}$ Hyun-Min Kim, ${ }^{1}$ Shangtong Li, ${ }^{3}$ Leticia Labrador, ${ }^{2}$ \\ James Lightfoot, ${ }^{2}$ Maxim V. Gerashchenko, ${ }^{4}$ Vyacheslav M. Labunskyy, ${ }^{5}$ Meng-Qiu Dong, ${ }^{3}$ \\ Enrique Martinez-Perez, ${ }^{2}$ and Monica P. Colaiácovo ${ }^{1}$ \\ ${ }^{1}$ Department of Genetics, Harvard Medical School, Boston, Massachusetts 02115, USA; ${ }^{2}$ Medical Research Council Clinical \\ Sciences Centre, Imperial College London, London W12 0NN, United Kingdom; ${ }^{3}$ College of Life Science, Beijing Normal \\ University, Beijing 100875, China; National Institute of Biological Sciences, Beijing 102206, China; ${ }^{4}$ Division of Genetics, \\ Department of Medicine, Brigham and Women's Hospital, Harvard Medical School, Boston, Massachusetts 02115, USA; \\ ${ }^{5}$ Department of Dermatology, Boston University School of Medicine, Boston, Massachusetts 02218, USA
}

\begin{abstract}
$\mathrm{N}$-terminal acetylation of the first two amino acids on proteins is a prevalent cotranslational modification. Despite its abundance, the biological processes associated with this modification are not well understood. Here, we mapped the pattern of protein N-terminal acetylation in Caenorhabditis elegans, uncovering a conserved set of rules for this protein modification and identifying substrates for the $\mathrm{N}$-terminal acetyltransferase $\mathrm{B}$ (NatB) complex. We observed an enrichment for global protein N-terminal acetylation and also specifically for NatB substrates in the nucleus, supporting the importance of this modification for regulating biological functions within this cellular compartment. Peptide profiling analysis provides evidence of cross-talk between $\mathbf{N}$-terminal acetylation and internal modifications in a NAT substrate-specific manner. In vivo studies indicate that $\mathrm{N}$-terminal acetylation is critical for meiosis, as it regulates the assembly of the synaptonemal complex $(\mathrm{SC})$, a proteinaceous structure ubiquitously present during meiosis from yeast to humans. Specifically, $\mathrm{N}$-terminal acetylation of NatB substrate SYP-1, an SC structural component, is critical for SC assembly. These findings provide novel insights into the biological functions of N-terminal acetylation and its essential role during meiosis.
\end{abstract}

[Keywords: NatB complex; N-terminal acetylation; synaptonemal complex; meiosis; C. elegans]

Supplemental material is available for this article.

Received January 4, 2016; revised version accepted October 20, 2016.

Cotranslational $\mathrm{N}$-terminal processing is a prevalent and important step of protein maturation, including removal of the initiator methionine (iMet) by methionine aminopeptidases (MetAPs) and acetylation of the exposed $\mathrm{N}-\alpha-$ amino group on the first amino acid by a group of conserved N-terminal acetyltransferases (NATs). The substrate specificities of MetAPs and NATs are defined mainly by the amino acids following iMet (Polevoda et al. 1999). About $50 \%-70 \%$ of proteins are $\mathrm{N}$-terminally acetylated in yeast, and $80 \%-90 \%$ of the soluble proteins are $\mathrm{N}$-terminally acetylated in human cells (Arnesen et al. 2009; Van Damme et al. 2011). Mutations in NATs are associated with various phenotypes in different organisms, including in humans, where mutations in NAA10, the catalytic subunit of NatA, lead to a global developmental delay and Ogden and Lenz microphthalmia syndromes (Rope et al. 2011; Esmailpour et al. 2014; Myklebust

Corresponding author: mcolaiacovo@genetics.med.harvard.edu Article published online ahead of print. Article and publication date are online at http://www.genesdev.org/cgi/doi/10.1101/gad.277350.116. et al. 2015; Popp et al. 2015). Despite its abundance, the molecular functions of this modification have been characterized for only a handful of cases, where N-terminal acetylation can affect protein targeting to membranes, protein-protein interactions, protein folding, or protein degradation (Urbancikova and Hitchcock-DeGregori 1994; Setty et al. 2004; Arnesen et al. 2010; Hwang et al. 2010; Scott et al. 2011; Holmes et al. 2014). However, the extent to which these specific functions operate in the proteome remains unclear.

The synaptonemal complex (SC) is a meiosis-specific tripartite proteinaceous structure that is conserved at the ultrastructural level and in its role of promoting interhomolog crossover recombination, which is critical for both obtaining genetic diversity in the population and

(C) 2016 Gao et al. This article is distributed exclusively by Cold Spring Harbor Laboratory Press for the first six months after the full-issue publication date (see http://genesdev.cshlp.org/site/misc/terms.xhtml). After six months, it is available under a Creative Commons License (Attribution-NonCommercial 4.0 International), as described at http:// creativecommons.org/licenses/by-nc/4.0/. 
the proper segregation of the homologous chromosomes away from each other at meiosis I (Page and Hawley 2004; Zickler and Kleckner 2015). SC formation is complex and involves the establishment of meiotic chromosome axes between sister chromatids and the assembly of central region components connecting homologous chromosome axes together. Defects in SC formation result in a lack of crossovers as well as errors in meiotic chromosome segregation across organisms and can lead to infertility, miscarriages, and birth defects in humans (Hassold et al. 2007; Zickler and Kleckner 2015). Despite the importance of SC formation for reproductive health, the mechanisms regulating its assembly are poorly understood.

In this study, we mapped the global N-terminal acetylation pattern in the Caenorhabditis elegans proteome and identified substrates for NatB, providing a valuable database for future studies. Moreover, the functional significance of protein $\mathrm{N}$-terminal acetylation is underscored by our discovery of its requirement for the formation of the SC during meiosis.

\section{Results}

Mapping of global $N$-terminal acetylation in $\mathrm{C}$. elegans reveals a conserved set of rules for this type of modification

We previously identified CRA-1 as an ortholog of human NAA25 (the noncatalytic subunit of the NatB complex) and discovered that it regulates chromosome synapsis during meiosis through an unknown molecular mechanism (Smolikov et al. 2008). We also identified a putative C. elegans ortholog of human NAA20 (the catalytic subunit of the NatB complex), NATB-1 (Y97E10AL.3), in a screen for meiotic candidates (see the Materials and Methods). Moreover, reciprocal immunoprecipitation experiments and Western blot analysis demonstrated a physical interaction between CRA-1 and NATB-1 (Supplemental Fig. S1). These observations suggest that CRA-1 and NATB-1 are the two constitutive subunits of the C. elegans NatB complex.

To further investigate the putative role of CRA-1 and NATB-1 as components of NatB, we first defined the overall profile of $\mathrm{N}$-terminal acetylation in C. elegans. Using the most advanced mass spectrometry (MS) technologies (Wisniewski et al. 2009; Michalski et al. 2011), we performed an in-depth analysis of the C. elegans proteome. Over 9000 proteins and $>120,000$ peptides (peptide false discovery rate $<0.2 \%$ ) were identified from whole-worm lysates. This allowed us to obtain a total of 10,247 spectra originating from 1233 distinct $\mathrm{N}$ termini of proteins in wild-type worms (Supplemental Table S1), covering 1393 of the 26,011 ORFs annotated in the C. elegans genome (WS233). This is comparable with what was achieved for the human and mouse proteomes by isolating N-terminal peptides, where termini from 2723 and 1708 distinct proteins were detected, respectively /Van Damme et al. 2014). In C. elegans, $74 \%$ of the termini are N-terminally acetylated, comparable with the levels of protein $\mathrm{N}$ - terminal acetylation observed for flies and humans (Arnesen et al. 2009; Goetze et al. 2009). We also identified significant $\mathrm{N}$-terminal phosphorylations $(0.6 \%)$ among our data set, while no N-terminal methylation or ubiquitination was identified (Fig. 1A-D).

Our data also revealed conserved features of $\mathrm{N}$-terminal processing that are shared across eukaryotic organisms. First, iMet removal is substrate-specific and is similar to what has been observed in yeast, flies, and humans (Arnesen et al. 2009; Goetze et al. 2009). iMet is removed when the second amino acid is uncharged and has a relatively short gyration radius (iMet $\Delta$ ): Gly, Ala, Ser, Thr, Cys, Val, or Pro (Fig. 1A). Only a small group of these termini $(2 \% ; n=8027$ spectra) maintains their iMet and is mostly unmodified (Fig. 1C). These termini could originate from ribosome-associated nascent peptides or mature proteins that failed to undergo proper N-terminal processing. In the other groups of proteins (iMet-Asp, iMet-Glu, iMetAsn, iMet-Gln, iMet-Lys, iMet-Arg, iMet-Phe, iMet-Tyr, iMet-Trp, iMet-Met, iMet-His, iMet-Leu, and iMet-Ile), iMet is largely maintained $(99.2 \% ; n=2220)$ (Fig. 1B). Of note, for most iMet-Lys and iMet-Arg proteins, the first two amino acids are not detectable due to trypsin digestion.

Second, the preference for $\mathrm{N}$-terminal acetylation is largely defined by the second amino acid. For example, a proline at the second position-or at the third position when the second position is a serine or alanine-blocks $\mathrm{N}$-terminal acetylation. This is known as the (X)PX rule identified in flies (Goetze et al. 2009). Most N termini with a valine at the second position $(92 \% ; n=458)$ are not modified, and the repulsion for acetylation of valine termini seems to be conserved across organisms (Arnesen et al. 2009; Goetze et al. 2009). However, unlike proline, the presence of valine at the third position does not affect $\mathrm{N}$-terminal acetylation in C. elegans (Supplemental Table S1). Similar to other organisms (Arnesen et al. 2009; Goetze et al. 2009), glycine termini are not favored substrates for acetylation, with only $\sim 50 \%$ being acetylated in C. elegans (Supplemental Table S1). Finally, only $~ 50 \%$ of threonine termini are acetylated in worms. However, while this group of termini is not favored for acetylation in yeast ( $36 \%$ acetylated), it is highly acetylated in flies ( 71\%) and humans ( 92\%) (Arnesen et al. 2009; Goetze et al. 2009). In conclusion, this analysis identified a critical set of rules for $\mathrm{N}$-terminal protein acetylation in C. elegans that is mostly conserved among organisms and established a valuable database (Supplemental Table S1) for future studies.

Identification of NatB substrates in C. elegans and of a potential interference between NATs for N-terminal acetylation

To identify NatB substrates in C. elegans, mapping of $\mathrm{N}$-terminal acetylation patterns was performed for $\mathrm{cra}-1$ and natb-1 mutants (Fig. 1E; Supplemental Tables S2, S3). Acetylation levels for four groups of $\mathrm{N}$ termini showed a significant reduction in both of the mutants compared with wild type: iMet-Asp, iMet-Glu, iMet- 
Gao et al.
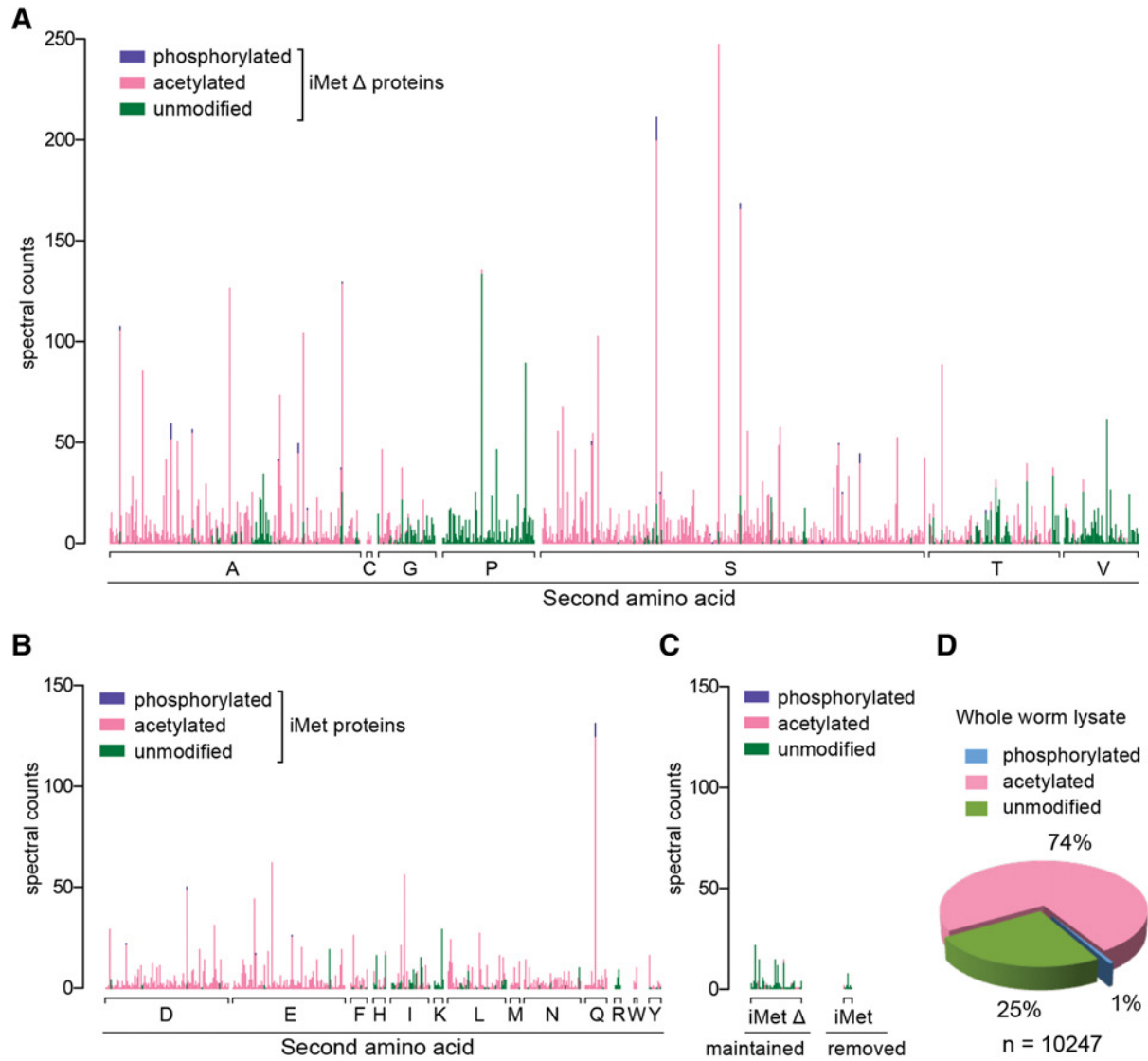

C

D

E

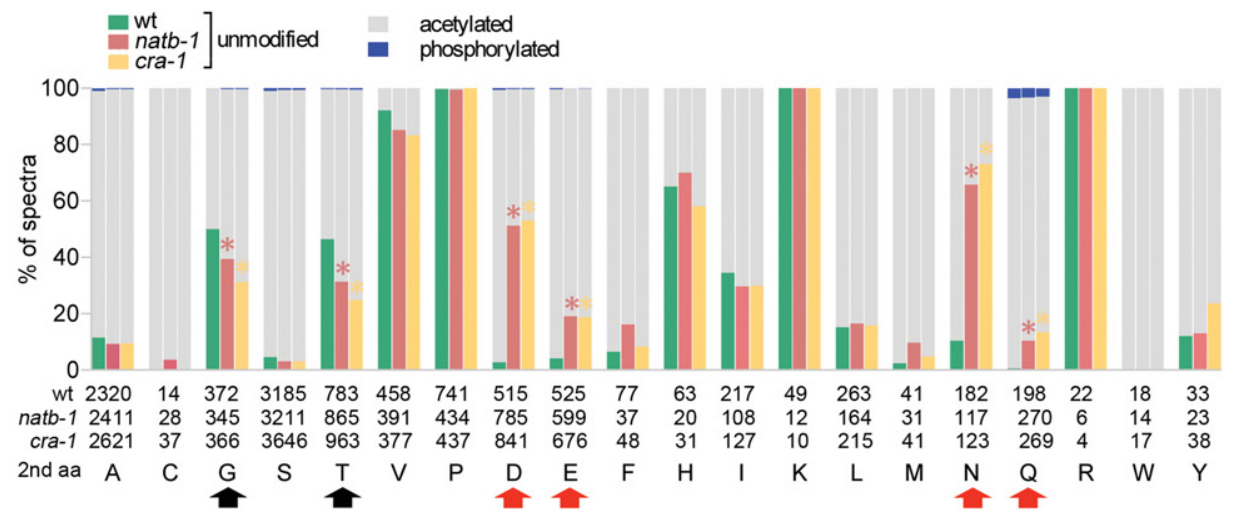

Figure 1. Mapping of $\mathrm{N}$-terminal modifications and identification of NatB substrates in C. elegans. (A) N-terminal acetylation patterns for iMet $\Delta$ proteins (where the iMet is removed) in wild-type worms. Each bar represents an individual N-terminal peptide with its corresponding spectral counts ( $Y$-axis). Phosphorylation is indicated in blue, acetylation is in pink, and unmodified peptides are in green. Peptides are ordered alphabetically among each group ( $X$-axis; grouped based on their second amino acids). A total of 796 distinct $\mathrm{N}$-terminal peptides, corresponding to 908 proteins, is represented in this graph. $(B) \mathrm{N}$-terminal acetylation pattern for iMet proteins. Data are presented as in $A$. A total of 416 distinct $\mathrm{N}$-terminal peptides, corresponding to 456 proteins, is shown. (C) Acetylation status for proteins that are normally iMet $\Delta$ proteins and instead maintained their iMet (left group; 14 distinct $\mathrm{N}$-terminal peptides) and for iMet proteins that are missing their iMet (right group; seven distinct N-terminal peptides). The low numbers of peptides identified for the two groups suggest that iMet removal is tightly regulated. $(D)$ Summary of $\mathrm{N}$-terminal modifications in C. elegans, where $n$ indicates the total number of spectral counts detected from whole-worm lysates. This analysis revealed that a large percentage of the proteins in $C$. elegans undergo $\mathrm{N}$-terminal acetylation and that $1 \%$ undergo $\mathrm{N}$-terminal phosphorylation. $(E)$ Comparison of protein $\mathrm{N}$-terminal modification levels detected in wild type and NatB mutants. Numbers on the $X$-axis represent the total spectral counts of $\mathrm{N}$-terminal peptides for each group of proteins (grouped based on their second amino acids). This analysis shows that MD, ME, MN, and MQ are preferred for NatB-mediated Nterminal acetylation (indicated by red arrows). A statistically significant increase in the levels of N-terminally acetylated proteins starting with MG and MT in the absence of NatB suggests that other NATs may be compensating for the absence of NatB activity (indicated by black arrows). $\left(^{*}\right) P<0.0001, \chi^{2}$ test. 
Asn and iMet-Gln termini were reduced for acetylation between $15 \%$ and $63 \%$, suggesting that these are NatB substrates in C. elegans. These groups of termini are also defined as NatB substrates in budding yeast and humans (Van Damme et al. 2012), suggesting a conservation of N-terminal acetylation specificity. However, partial acetylation of NatB substrates was still observed in the null mutants $(27 \%-80 \%)$, suggesting potential redundancies between NatB and other NATs, consistent with previous observations in yeast (Van Damme et al. 2012). Importantly, the decrease in N-terminal acetylation observed in natb-1 mutants mimicked that of cra-1 mutants, consistent with the hypothesis that CRA-1 and NATB-1 are the constitutive subunits of the NatB complex in worms.

Interestingly, acetylation levels for two of the termini $\left(\mathrm{Gly}^{-}\right.$and $\left.\mathrm{Thr}^{-}\right)$that are defined as NatA substrates were significantly increased $(11 \%-22 \%)$ in cra-1 and natb-1 mutants but to different levels compared with wild type (Fig. 1E). These observations suggest a potential interference between NATs for N-terminal acetylation (see the Discussion).

\section{Global protein abundances and turnover rates for NatB substrates are not affected in NatB mutants}

To understand the general function of N-terminal acetylation, we examined the role of $\mathrm{N}$-terminal acetylation on protein abundances and turnover rates. Semiquantitative analysis of MS data for whole-worm lysates suggests that the global protein abundances of NatB substrates are not affected in NatB mutants compared with wild type (Supplemental Fig. S2A,B), consistent with yeast data (Helbig et al. 2010). Given that N-terminal acetylation is a cotranslational process and that protein levels are controlled by both their translational rates and rates of degradation, we performed ribosome profiling (Ingolia et al. 2012) to determine whether protein translational rates might be affected in NatB mutants. Measurement of ribosome occupancies along mRNAs suggests that the global translational rates of NatB substrates are not affected in NatB mutants (Supplemental Fig. S2C,D). Collectively, these data indicate that the protein abundances and turnover rates for NatB substrates are not widely affected in NatB mutants. Of note, neither protein abundance nor translational rates for other known/putative subunits of NATs are affected in NatB mutants (Supplemental Fig. S2E,F).

\section{$N$-terminal acetylation mapping shows an enrichment for this modification in the nucleus}

To further understand the molecular functions of N-terminal acetylation, we examined whether $\mathrm{N}$-terminally acetylated proteins might be enriched in the nucleus. To this end, we isolated the nuclear fraction from young adult worms and treated it with Triton X-100 to remove soluble proteins (Supplemental Fig. S3). The nuclear fraction was analyzed by MS to identify its protein composition and Nterminal acetylation pattern. Gene ontology (GO) analysis of the 300 most abundant proteins identified indicates an enrichment for nuclear proteins (exemplified by "nuclear part," "nuclear pore," "nuclear envelope," and "nucleolus") and a lower proportion of cytosolic components (such as "cytoplasmic part," "cytoplasm," "cytosol," and "mitochondrion") in the nuclear fraction compared with whole-worm lysates (Supplemental Table S4). Moreover, cell cytoskeleton components were also found in the nuclear fraction, with GO terms such as "cytoskeleton," "actin cytoskeleton," and "contractile fiber part" being identified, suggesting association of cell cytoskeleton with the isolated nuclei. Interestingly, a significantly higher level of $\mathrm{N}$-terminal acetylation $182 \% ; n=4501$ spectra) was observed in this nuclear fraction compared with whole-worm lysates $\left(74 \% ; n=10247 ; P<0.0001\right.$, $\chi^{2}$ test) (Fig. 2A; Supplemental Table S5). Moreover, the increase in total acetylation levels represents a global alteration of the $\mathrm{N}$-terminal acetylation pattern: a decrease in the levels of acetylation-unfavored $\mathrm{N}$ termini $\left(\mathrm{Gly}^{-}, \mathrm{Pro}^{-}\right.$, $\mathrm{Thr}^{-}$, and $\mathrm{Val}^{-}$) and their unmodified portions and an increase of acetylation-favored termini $\left(\mathrm{Ser}^{-}\right.$, iMet-Asp ${ }^{-}$ and iMet-Glu ${ }^{-}$) (Fig. 2B). These data suggest an enrichment for protein $\mathrm{N}$-terminal acetylation in the nucleus, suggesting that $\mathrm{N}$-terminal acetylation may be important for the regulation of molecular functions within this cellular compartment.

Analysis of the proteins that are relatively enriched (enrichment index $>2$ compared with the whole-worm lysates) in the nuclear fraction reveals a significant enrichment for NatB substrates compared with proteins whose levels are decreased (enrichment index $<0.5$ ) in the nuclear fraction $\left(P=6.89 \times 10^{-7}, \chi^{2}\right.$ test $)$ or proteins identified in the whole-worm lysates $\left(P=3.74 \times 10^{-7}, \chi^{2}\right.$ test) (Fig. 2C-E), suggesting that $\mathrm{N}$-terminal acetylation of NatB substrates may be widely important for nuclear functions.

\section{Peptide profiling identifies a complex $N$-terminal processing network}

Stable protein-protein interactions are usually mediated by interaction surfaces that contain several amino acids and may therefore be regulated by $\mathrm{N}$-terminal acetylation in combination with modifications at more internal amino acids adjacent to protein $\mathrm{N}$ termini. To gain insights into this relationship, we performed peptide profiling along the lengths of proteins for wild-type worms and the NatB mutants, given that the MS used earlier in this study focused only on modifications at the first amino acid.

Interestingly, N-terminal region-specific alterations of peptide profiles encompassing the first 15 amino acids were observed for several groups of proteins in NatB mutants (Fig. 3A). Three groups of NatB substrates (MD, $\mathrm{ME}$, and $\mathrm{MQ}$ ) show similar significant increases in the spectral counts at the $\mathrm{N}$-terminal region in NatB mutants compared with wild type. Peptide profiles for other major iMet groups (MN, MK, MR, ML, MI, and MF) were not affected in NatB mutants. The alterations in N-terminal profiles represent global effects and are not caused by 

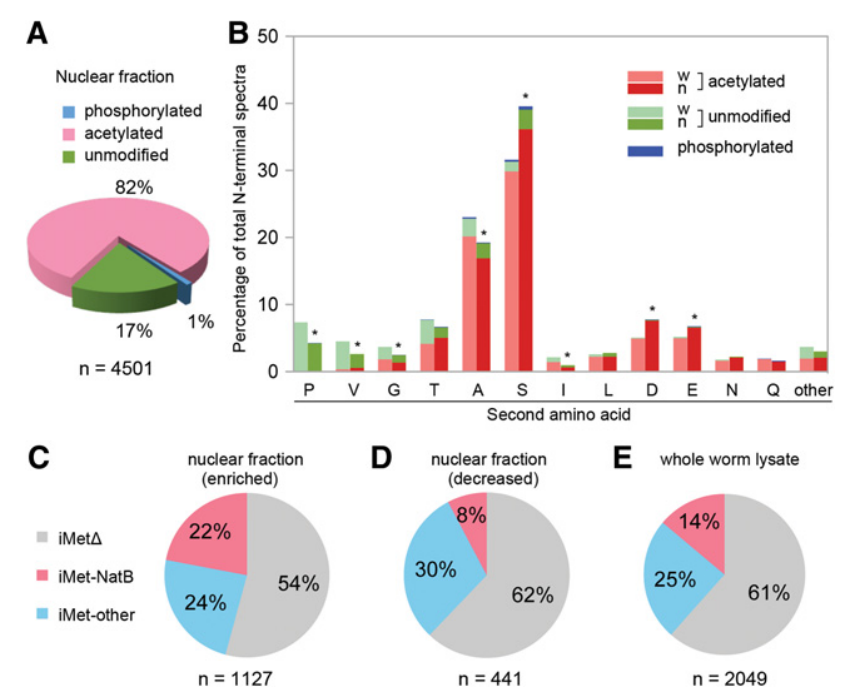

Figure 2. NatB substrates are enriched in the nuclear fraction. (A) Summary of the levels of $\mathrm{N}$-terminal modifications detected in the nuclear fraction, where $n$ indicates the total number of spectral counts identified for protein $\mathrm{N}$-terminal peptides. This analysis reveals an enrichment for $\mathrm{N}$-terminally acetylated peptides in the nuclear fraction compared with the whole-worm lysates. $(B)$ Comparison of $\mathrm{N}$-terminal acetylation levels (percentage, $Y$-axis) between whole-worm lysates $(\mathrm{w})$ and the nuclear (n) fraction suggests an overall shift of N-terminal acetylation profile. Peptides were grouped based on the second amino acid following the iMet, as indicated on the $X$-axis. "Other" corresponds to the sum of the $\mathrm{N}$-terminal peptide groups that are not shown individually (i.e., groups where the second amino acids were $\mathrm{C}, \mathrm{F}, \mathrm{H}, \mathrm{K}, \mathrm{M}, \mathrm{R}, \mathrm{W}$, or $\mathrm{Y}) .\left(^{*}\right) P<0.001, \chi^{2}$ test. $C-E$ show an enrichment for proteins that retain their iMet being NatBacetylated at their $\mathrm{N}$ terminus in the nuclear fraction. (C) Proteins whose levels are enriched in the nuclear fraction were grouped based on whether they had the iMet removed (iMet $\Delta$ ), had their $\mathrm{N}$ terminus modified by NatB (iMet-NatB), or were modified by another NAT (iMet-other). $n$ indicates the total number of proteins that were enriched in the nuclear fraction relative to whole-worm lysates. $(D)$ Distribution of the proteins whose levels are decreased in the nuclear fraction. This may represent either proteins that are present in the nucleus but do not form stable structures that can resist the detergent wash or proteins that are not enriched in the nucleus. $n$ indicates the total number of proteins whose levels are decreased in the nuclear fraction relative to whole-worm lysates. (E) Distribution of the most abundant proteins (threshold defined as at least 30 peptides identified for each protein) detected from whole-worm lysates.

changes in a few highly abundant substrates of NatB (Fig. $3 \mathrm{~B}, \mathrm{C})$. Surprisingly, peptide profiles for some groups of iMet $\Delta$ proteins (MA, MS, and MT) also show N-terminal region-specific increases in NatB mutants but to different levels, with consistently higher $\mathrm{N}$-terminal peptide enrichments observed for cra-1 mutants. The differences observed in peptide profiles are not likely caused by different abilities to detect $\mathrm{N}$ - $\boldsymbol{\alpha}$-acetylated peptides and unmodified peptides by MS (Fig. 3C). Moreover, the possibility that changes in the pool of ribosome-associated nascent peptides may account for the different profiles was excluded by ribosome profiling analysis, where no difference of ri- bosome coverage densities was observed at the $5^{\prime}$ regions of the coding sequences between wild type and NatB mutants (Supplemental Fig. S4). However, it is possible that the presence of multiple modifications along the span of 15 amino acids being examined can lead to a shift of the peptide mass. This would render this peptide undetectable by MS for the specific set of parameters used in this analysis (see the Materials and Methods), and, as a result, the total spectral counts for the corresponding peptide would be underrepresented. Therefore, the N-terminal region-specific increase for certain peptide profiles in the NatB mutants compared with the wild type may be the result of a reduction in the levels of internal modifications occurring along these $\mathrm{N}$-terminal regions in the mutants. These NAT substrate-specific alterations of N-terminal peptide profiles thus suggest a potential cross-talk between N-terminal acetylation (either NatB complex or $\mathrm{N}$-terminal acetyl group) and adjacent modifications (cotranslational or post-translational regulation), revealing a complex $\mathrm{N}$-terminal processing network.

\section{$N a t B$ is required for SC assembly}

Having shown that CRA-1 and NATB-1 function as part of the NatB NAT complex in C. elegans and knowing that SC assembly is severely affected in cra-1 mutants (Smolikov et al. 2008), we investigated whether NatB function is directly involved in promoting proper formation of the SC during meiosis. Indicative of a lack of crossover formation, 11-12 DAPI-stained bodies (univalents) were observed in oocytes at diakinesis in the cra-1 and natb-1 mutants instead of the six pairs of attached homologous chromosomes (bivalents) observed in wild type (Fig. 4A). Similar to $c r a-1$ mutants, natb-1 mutants also exhibited a high embryonic lethality $(98.7 \% ; n=5414)$ and defects in SC assembly (Fig. 4B; Smolikov et al. 2008). Specifically, while the assembly of axis-associated components (HTP-1/2/3 and SMC-1) was normal (Fig. 4B; data not shown), the assembly of central region components such as SYP-1 was delayed in cra-1 and natb-1 mutants (Supplemental Fig. S5). Moreover, during mid-pachytene to late pachytene, instead of the uniformly continuous linear tracks formed by SYP-1 at the interface between homologs in wild type, SYP-1 was unevenly distributed throughout chromatin tracks in cra-1 and natb-1 mutants, forming foci and both long and short stretches of variable signal intensity (Fig. 4B). These defects in SC assembly observed in cra-1 and natb-1 mutants are different from those observed in null mutants for any of the four (syp$1 / 2 / 3 / 4$ ) central region components of the SC. The SYPs are interdependent for their chromosome localization, and none of the four SYP proteins can be detected on the chromosomes in any of the syp-null mutants (Smolikov et al. 2007, 2009). Finally, cra-1(RNAi);natb-1 double mutants exhibit SC assembly defects that are indistinguishable from either single mutant (Fig. 4B), further supporting the idea that CRA-1 and NATB-1 function together to promote SC assembly and crossover formation possibly by mediating protein $\mathrm{N}$-terminal acetylation. 
A
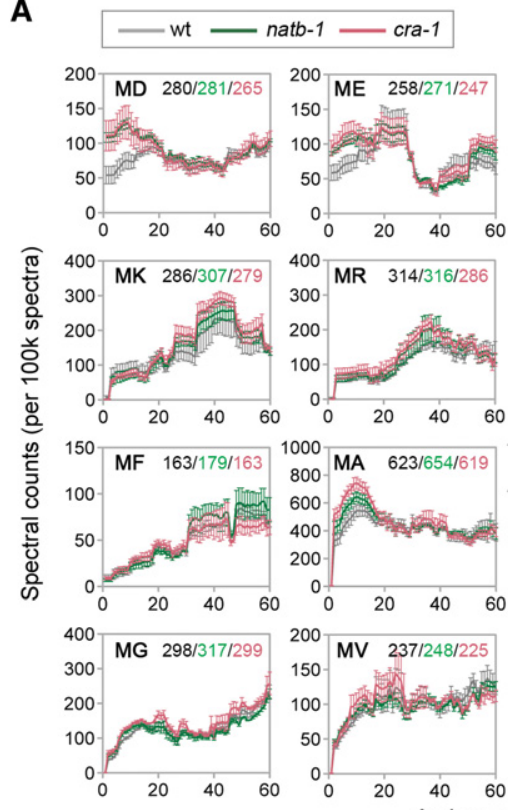

$$
\text { Amin }
$$

B

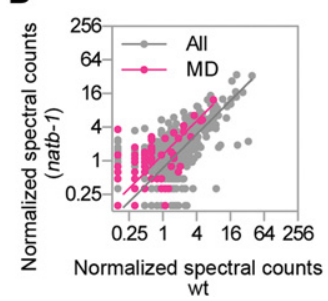

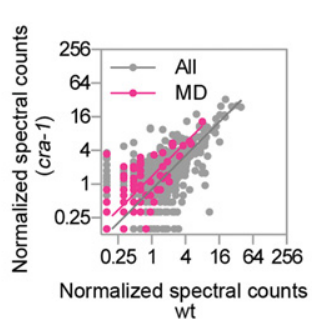

wt
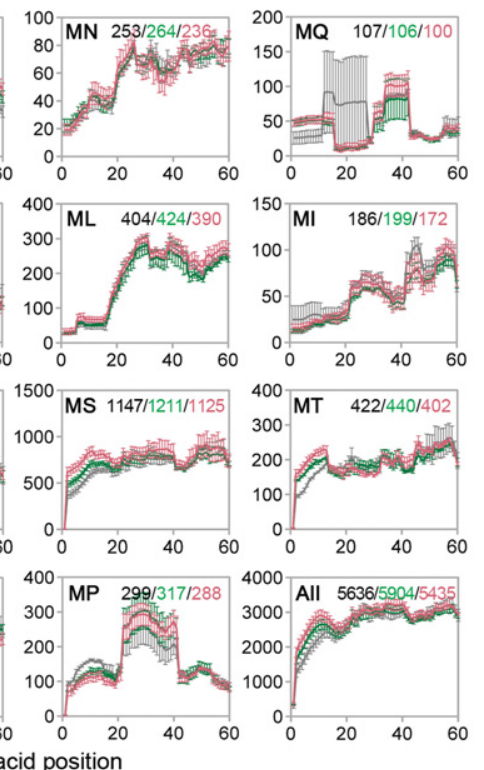

C

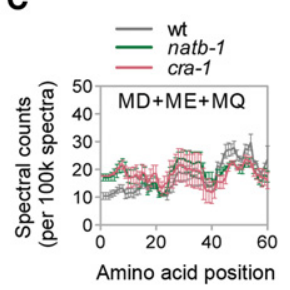

Figure 3. Peptide profiling reveals cross-talk between $\mathrm{N}$-terminal acetylation and internal modifications. $(A)$ Protein N-terminal peptide profiling reveals N-terminal region-specific alterations between wild type and $\mathrm{NatB}$ mutants. The data shown encompass the first 60 amino acids $(X$-axes) for proteins, starting with the two amino acids indicated in the top left corner of every graph. Values on the $Y$-axes indicate the representation of the amino acid position among the detected spectra. The numbers of proteins included in the analysis are indicated in the top right corners. Data represent mean \pm SEM from three biological replicates. Low abundant groups are not shown (MC, MH, MM, MW, and MY). "All" represents data for all detected proteins combined. $(B)$ Comparison of normalized N-terminal spectral counts (per 100,000 spectra) between wild type and natb-1 mutants (left) or wild type and cra-1 mutants (right) shows that alterations in $\mathrm{N}$-terminal peptide profiles do not result from changes in just some abundant proteins but represent a global alteration. $(C)$ Peptide profiles for proteins with a histidine (His) in the first $10 \mathrm{~N}$-terminal amino acids suggest that the differences in $\mathrm{N}$-terminal profiles are not a result of different abilities of MS to identify $\mathrm{N}$-terminally unmodified or acetylated peptides. Because the histidine amino acid is positively charged, the presence of a histidine at the $\mathrm{N}$-terminal region ensures that the $\mathrm{N}$-terminal peptides have enough charges to be identified by MS even when the $\mathrm{N}$-terminal amino group is neutralized by acetylation.
Protein levels for SC components are not affected in NatB mutants

To determine how $\mathrm{N}$-terminal acetylation regulates SC assembly, we first determined whether protein levels for SC components are affected in NatB mutants. We focused on four known components of the SC that our identification of the rules defining NAT targets indicate are putative NatB substrates: the axis-associated HORMA domain protein HTP-3 and three central region components (SYP-1, SYP-2, and SYP-3). Western blot analysis suggests that HTP-3, SYP-1, and SYP-2 protein levels are not affected in NatB mutants (Supplemental Fig. S6A), consistent with the global MS analyses that indicated that protein abundances of NatB substrates are not affected in NatB mutants (we were precluded from assessing SYP-3 in this manner because the antibodies available do not work on Westerns). Ribosome densities for $h t p-3$, syp-1, and syp-2 were also not affected in NatB mutants (Supplemental Fig. S6B). A 50\% increase in ribosome density was observed for syp-3 in NatB mutants. However, such an increase in translation does not likely cause synapsis defects given that otherwise wild-type worms expressing a functional additional copy of tagged syp-3 do not exhibit synapsis defects (Rog and Dernburg 2015). These analyses suggest that the defects in SC assembly observed in NatB mutants are not likely caused by alterations in SC protein levels.
$N$-terminal acetylation of SYP-1 is required for SC assembly

To further examine how protein $\mathrm{N}$-terminal acetylation impacts SC assembly, we hypothesized that NatB-mediated $\mathrm{N}$-terminal acetylation of some SC components might be required for protein-protein interactions. Our previous study of the organization of the central region components of the SC in C. elegans revealed that the $\mathrm{N}$-terminal domain of SYP-1 is located at the middle of the central region with its $\mathrm{C}$-terminal domain facing toward the lateral elements (Schild-Prufert et al. 2011). This is similar to the organization of SC transverse filaments in other organisms (Liu et al. 1996; Schmekel et al. 1996; Dong and Roeder 2000; Anderson et al. 2005), suggesting a conserved feature for SC transverse filament organization. The N-terminal domains of SC transverse filament proteins could play a role in fully bridging or "zipping up" the SC. Interestingly, analysis of SYP protein localization in the NatB mutants showed that the central region proteins localize to both paired and unpaired chromosome axes (Supplemental Fig. S7; Smolikov et al., 2008; data not shown), indicating that the association between central region proteins and chromosome axes is not abolished in the NatB mutants. Instead, the connection between the pairs of homologous axes with associated SYP proteins might be impaired at the middle of the central region in the NatB mutants. Given the conserved feature for SC 


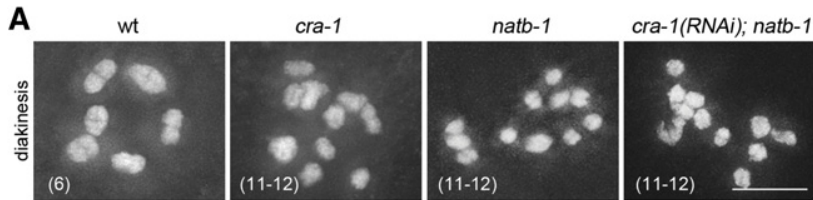

B
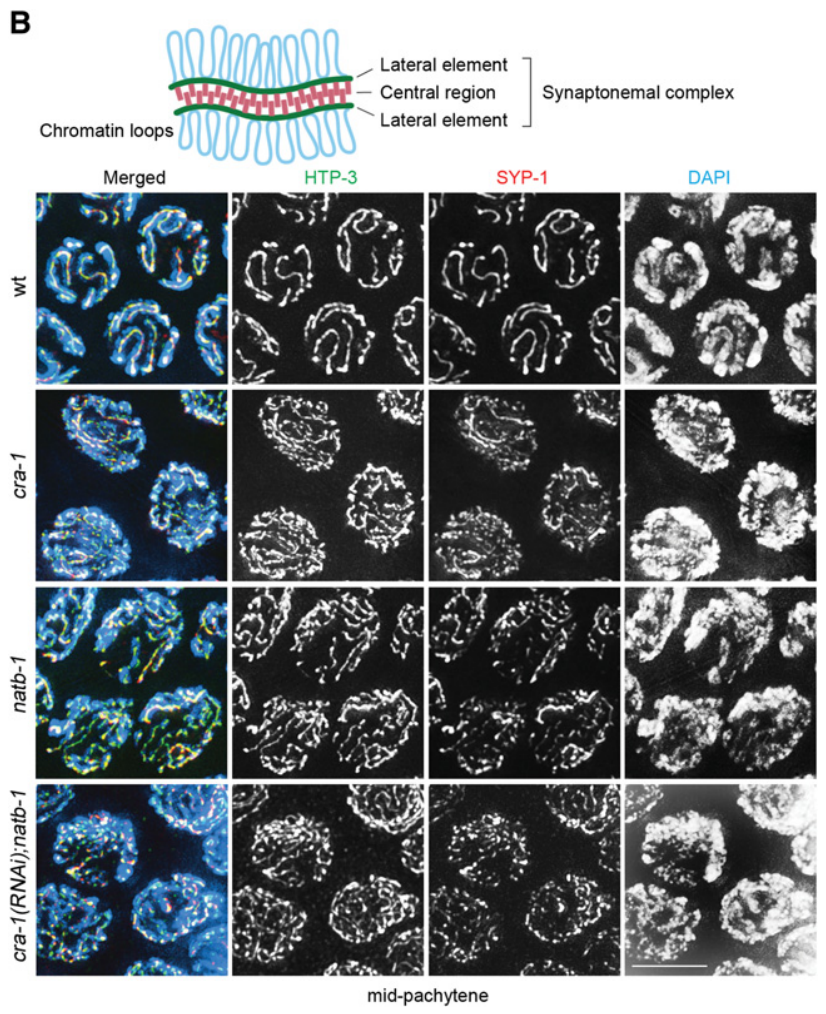

Figure 4. NatB is required for SC assembly. (A) DAPI-stained bodies in -1 oocytes at diakinesis in the indicated genotypes. The numbers of observed DAPI-stained bodies are indicated in parentheses. Instead of the six DAPI-stained bodies corresponding to the six pairs of attached bivalents observed in wild type, the increased numbers of DAPI-stained bodies suggest a lack of crossovers in the NatB mutants. $n>30-1$ oocytes scored per genotype. Bar, $5 \mu \mathrm{m}$. (B) Immunolocalization of HTP-3 (green) and SYP-1 (red) in mid-pachytene nuclei of gonads dissected from the indicated genotypes. The thin DAPI-stained chromosome tracks accompanied by evidence of separated chromosome axes, as revealed by HTP-3 staining and discontinuous SYP-1 localization, indicate impaired chromosome synapsis that is indistinguishable between NatB mutants. Bar, $5 \mu \mathrm{m}$.

transverse filament organization and the defect in SC assembly observed in NatB mutants, our further analysis focused on the role of N-terminal acetylation on SYP-1.

Our global mapping of protein N-terminal acetylation did not identify the SYP-1 N terminus likely because a trypsin digestion was applied, which does not generate SYP-1 peptides of ideal length for MS identification. Since the SYP proteins interact with each other (Schild-Prufert et al. 2011), we performed SYP-2::GFP pull-downs from nuclear extracts from syp-2::gfp transgenic worms, which show normal SC assembly and crossover formation (Supplemental Fig. S8). Purified proteins were digested with the protease Glu-C and analyzed by MS. This al- lowed us to identify SYP-1 protein and its N-terminal peptides, which are $\mathrm{N}$ - $\alpha$-acetylated (Fig. 5A). Moreover, no unmodified N-terminal peptide was identified for SYP-1, suggesting that this protein is efficiently $\mathrm{N}$-terminally acetylated in vivo. A similar analysis was performed from worms depleted for cra-1 by RNAi, revealing the presence of unacetylated N-terminal peptides of SYP-1, supporting the hypothesis that $\mathrm{N}$-terminal acetylation of SYP-1 is NatB-dependent (Fig. 5B).

To test the in vivo role of SYP-1 N-terminal acetylation, we first took advantage of the conserved proline rule, in which proteins cannot be $\mathrm{N}$-terminally acetylated when the second amino acid is a proline (Goetze et al. 2009). Specifically, we generated syp-1 $1^{D 2 P}$ transgenic worms where a single copy of syp-1 containing a proline instead of an aspartate at the second amino acid was inserted into chromosome II in a worm also expressing wild-type syp-1 from its endogenous locus. These transgenic worms exhibit meiotic defects similar to, albeit not as severe as, those observed in cra-1 and natb-1 mutants, including delayed and incomplete assembly of the central region components of the SC (Fig. 6A; Supplemental Fig. S9) and the presence of univalents in diakinesis oocytes, indicating a lack of crossovers (Fig. 6B). Importantly, the defects observed in $s y p-1^{D 2 P}$ worms are not a result of protein overexpression, since replacing the mutated syp-1 with an additional wild-type copy of syp-1 did not impair either synapsis or crossover formation, as indicated by the presence of six bivalents in diakinesis oocytes (Fig. 6A,B).

To examine the phenotypes in worms expressing only the mutated SYP-1 protein, we tried two different strategies. One consisted of crossing the syp-1 $1^{D 2 P}$ transgene into a syp-1-null mutant background. However, worms carrying the syp-1 $1^{D 2 P}$ transgene in a background homozygous for the syp-1-null allele were never obtained (144 F2 worms screened). We were also unable to create the syp$1^{D 2 P}$ mutation by CRISPR-Cas9 genomic editing (>800 F1 screened) (Norris et al. 2015). These outcomes suggest that the potential dominant effects exerted by the mutation and the elevated embryonic lethality and/or larval lethality associated with it might preclude this analysis. This is also supported by our earlier observation of a similar albeit less severe defect in syp-1 $1^{D 2 P}$ transgenic worms, where the wild-type SYP-1 protein is still present. Importantly, we succeeded in generating CRISPR-engineered mutants (htp-3 $3^{D 2 P}$ and SMC1/him-1 $\left.{ }^{R 2 P}\right)$ where the second amino acids were also mutated to a proline for other proteins required for chromosome synapsis (Chan et al. 2003; Goodyer et al. 2008; Severson et al. 2009). SC assembly is not affected in these mutants (Supplemental Fig. S10), suggesting that $\mathrm{N}$-terminal acetylation of these proteins is not essential for SC assembly and that altering the second amino acid of a protein does not necessarily affect protein function.

We also applied another strategy to test the in vivo role of $\mathrm{N}$-terminal acetylation by inserting a GFP tag at the $\mathrm{N}$-terminal end of SYP-1 by CRISPR (Norris et al. 2015). Interestingly, in worms homozygous for the GFP insertion, we observed severe synapsis defects, only GFP-SYP-1 foci instead of continuous GFP-SYP-1 tracks in meiotic prophase 
A

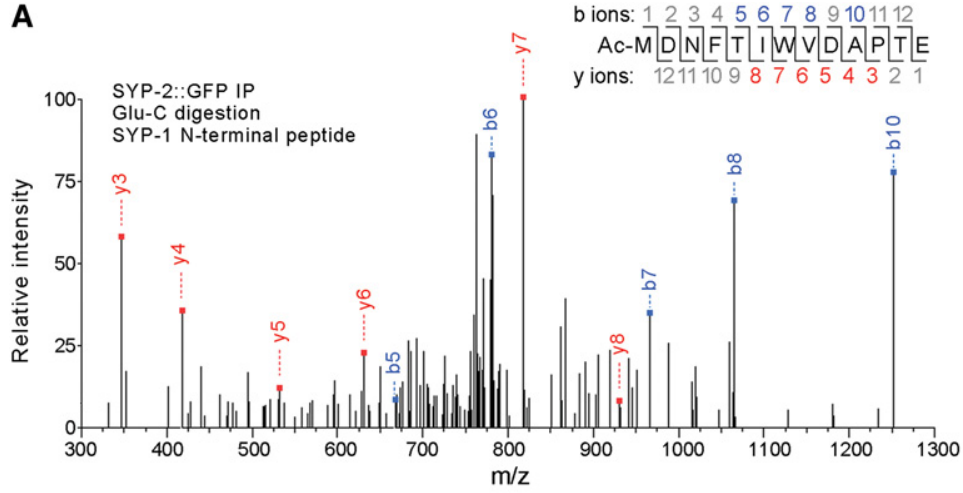

B

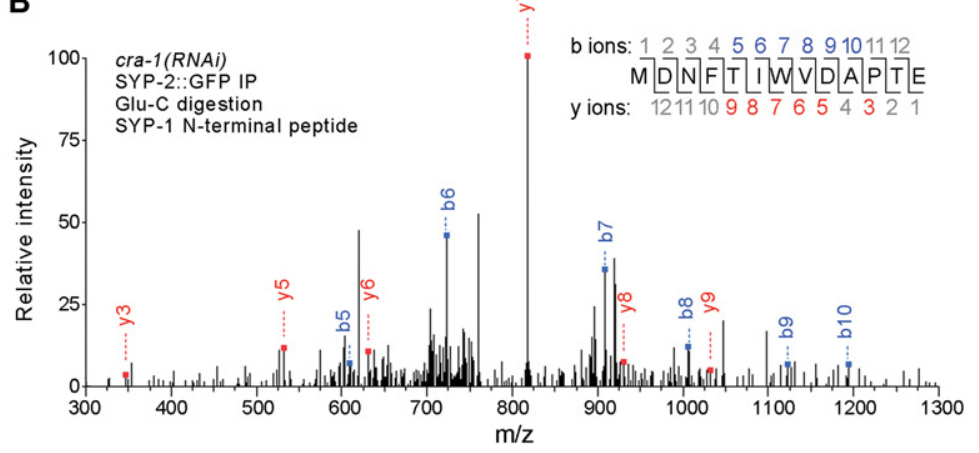

Figure 5. SYP-1 is $\mathrm{N}$-terminally acetylated in vivo. $(A)$ Liquid chromatography-tandem MS (LC-MS/MS) spectrum for the N-terminal peptide of SYP-1 (MDNFTIWVDAPTE) after Glu-C digestion in the range of 300-1300 $\mathrm{m} / \mathrm{z}$. Single charged $\mathrm{y}$ (red) and b (blue) ions used to match the peptide sequence with $\mathrm{N}$-terminal acetylation are annotated. "b ions" were generated through fragmentation of the peptide bond from the $\mathrm{N}$ terminus, and " $\mathrm{y}$ ions" were generated through fragmentation of the peptide bond from the C terminus. Endogenous SYP-1 was copurified with SYP-2::GFP by anti-GFP immunoprecipitation from extracts of isolated nuclei of syp-2::gfp transgenic worms. $(B)$ LC-MS/MS identification of unmodified N-terminal peptides of SYP-1 (MDNFTIWVDAPTE) from cra-1(RNAi) worms. nuclei, and, consistently, 12 DAPI-stained bodies in diakinesis nuclei (Fig. 6C,D), suggesting a complete disruption of crossover formation. These observations are consistent with the hypothesis that N-terminal acetylation of SYP-1 might be directly involved in mediating protein-protein interactions between SC components. Taken together, these data show that N-terminal acetylation of the transverse filament protein SYP-1 is required for assembly of the $\mathrm{SC}$, revealing a role for $\mathrm{N}$-terminal acetylation in establishing a stable macromolecular structure in the cells.

\section{Discussion}

Our data reveal a set of conserved rules for $\mathrm{N}$-terminal acetylation and provide a valuable searchable database for future studies. Moreover, our data support a complex interference network between different NATs and crosstalk between $\mathrm{N}$-terminal acetylation and modifications in adjacent amino acids at the $\mathrm{N}$-terminal regions of proteins (Fig. 7A). The biological significance of protein $\mathrm{N}$ terminal acetylation is underscored by its wide presence in the nucleus, where we demonstrate that it is critical for the assembly of a macromolecular structure, the SC, which is required for accurate chromosome segregation during meiosis (Fig. 7B).

\section{The conservation and complexity of protein \\ $N$-terminal processing}

By performing whole-worm proteomic analysis, we mapped protein N-terminal modifications in C. elegans. Our data revealed a set of conserved rules for $\mathrm{N}$-terminal processing, including methionine removal and $\mathrm{N}-\alpha$ acetylation. With an uncharged and relatively short gyration radius amino acid following the iMet (Gly, Ala, Ser, Thr, Cys, Val, or Pro), the iMet is efficiently removed (Fig. 1A-C). Moreover, preference for $\mathrm{N}$-terminal acetylation is also determined mainly by the property of the second amino acid of a protein. Proteins in which the second amino acid is either a proline or a valine are the most unfavorable proteins for $\mathrm{N}$-terminal acetylation, while the defined NatB substrates (i.e., MD, ME, MN, and MQ proteins) are groups of proteins showing the highest acetylation frequencies. However, it is possible that amino acids in other positions might affect the acetylation status of specific proteins. A known example is when a proline is present at the third position, in which case it can block N-terminal acetylation by NatA (Goetze et al. 2009).

Interestingly, in addition to $\mathrm{N}$-terminal acetylation, we also found $\mathrm{N}$-terminal phosphorylation as a significant modification ( $\sim 1 \%$ of the detected $\mathrm{N}$-terminal peptides). The function of phosphorylation in this context will need to be explored further. Moreover, while N-terminal acetylation is known to be a cotranslational process, it is not known whether $\mathrm{N}$-terminal phosphorylation is a cotranslational or post-translational process.

Comparing the $\mathrm{N}$-terminal acetylation patterns between wild type and the NatB mutants allowed us to identify redundancy and interference between NATs. The fact that residual/partial $\mathrm{N}$-terminal acetylation of NatB substrates is still detected in NatB mutants suggests a redundancy between NatB and other NATs, which has also been observed in other organisms (Van Damme et al. 2012). Redundancies between NATs may serve as a 


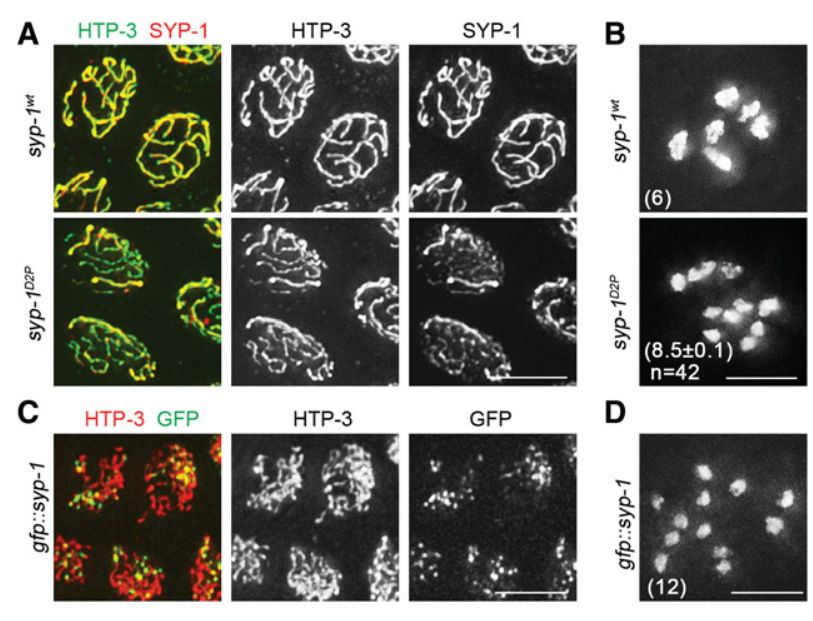

Figure 6. N-terminal acetylation of the SYP-1 protein is critical for SC assembly. (A) Immunolocalization of HTP-3 (green) and SYP-1 (red) in mid-pachytene nuclei of syp- $1^{\text {wt }}$ and $s y p-1^{D 2 P}$ transgenic worms shows discontinuous and reduced SYP-1 signal in syp-1 $1^{D 2 P}$ worms. These transgenic worms carry either a wildtype $\left(\right.$ syp- $\left.1^{\text {wt }}\right)$ or mutated $\left(s y p-1^{D 2 P}\right)$ syp-1 inserted into chromosome II while also expressing wild-type syp-1 from its endogenous locus. Bar, $5 \mu \mathrm{m}$. $(B)$ The number of DAPI-stained bodies observed in oocytes at diakinesis in syp- $1^{w t}$ and syp- $1^{D 2 P}$ transgenic worms reveals impaired crossover formation in $s y p-1^{D 2 P}$ worms. The numbers of DAPI-stained bodies are indicated in parenthesis $($ mean \pm SEM). $n>40$ oocytes scored per genotype. Bar, $5 \mu \mathrm{m}$. (C) HTP-3 (immunostaining; red) and GFP::SYP-1 (endogenous GFP fluorescent signal) localization in mid-pachytene nuclei of gfp::syp-1 worms reveals that a tag at the $\mathrm{N}$ terminus of SYP-1 also interferes with chromosome synapsis, possibly by impeding the acetylation of that $\mathrm{N}$ terminus. GFP::SYP-1 signal is observed forming only foci, and, as exemplified by the HTP-3 signal, chromosomes persist in the clustered configuration, consistent with an extended transition zone phenotype observed in synapsis-defective mutants. Bar, $5 \mu \mathrm{m}$. (D) DAPI-stained bodies in diakinesis nuclei in $g f p:: s y p-1$ worms reveal a lack of bivalent formation, indicating impaired crossover formation. Only 12 DAPI-stained bodies (univalents) were observed. $n=32$ oocytes scored. Bar, $5 \mu \mathrm{m}$.

mechanism to ensure efficient acetylation of their substrates. However, which NATs act redundantly with NatB remains unclear.

$\mathrm{N}$-terminal acetylation is known to be a cotranslational process, and NAT subunits associate with the ribosome to mediate N-terminal acetylation. However, the mechanism for how different NATs are coordinated for their association with the ribosome is not clear. Our study revealed interferences between NATs. Specifically, mutation in NatB can affect the acetylation levels of non-NatB substrates (Fig. 1E). Interestingly, mutations in the different NatB subunits did not result in identical effects on interfered non-NatB substrates. Consistently, mutation in the noncatalytic subunit CRA-1 caused a stronger effect than a mutation in the catalytic subunit NATB-1. As the noncatalytic subunits of NATs might be responsible for the recruitment of these complexes to the ribosome (Gautschi et al. 2003; Starheim et al. 2012), loss of this subunit might affect the way other NATs operate on the ribosome. Importantly, alteration of NAT expression has been found to be associated with cancers in humans (Kalvik and Arnesen 2013). Alterations of N-terminal acetylation profiles would be caused by abnormal expression of the NAT subunits.

\section{Understanding the global function of $N$-terminal acetylation}

Although prevalent, the general functions of $\mathrm{N}$-terminal acetylation are still not well understood. Previous studies have shown that $\mathrm{N}$-terminal acetylation can mediate protein degradation (Kim et al. 2014). However, our proteomic analysis suggests that global protein abundances of NatB substrates are not affected in NatB mutants. One possibility is that partial $\mathrm{N}$-terminal acetylation (up to $85 \%$ of wild-type levels) still takes place on NatB substrates in the mutants. Alternatively, NatB substrates may be stoichiometrically expressed and their $\mathrm{N}$ termini may be shielded from degradation by their $\mathrm{N}$-terminal binding partners (Shemorry et al. 2013).

A

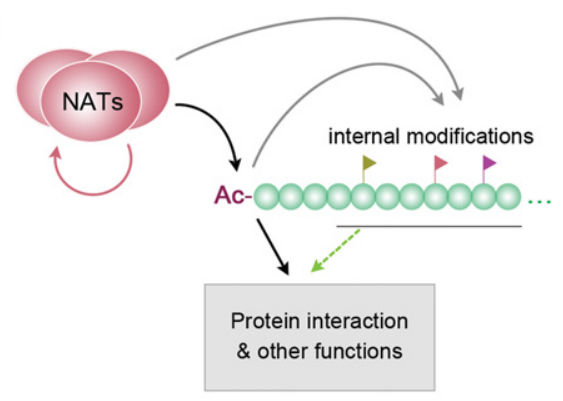

B

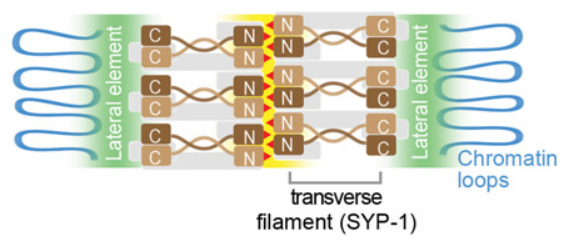

Figure 7. Models for the molecular function of N-terminal acetylation and its role in SC assembly. (A) Model showing how Nterminal acetylation and its cross-talk with internal modifications may affect different biological functions. Gray arrows indicate two potential pathways through which either $\mathrm{N}$-terminal acetylation or NATs may affect internal modifications. The red arrow represents the observed interference between different NATs for $\mathrm{N}$-terminal acetylation. The dotted green arrow indicates that internal modifications may function together with $\mathrm{N}$-terminal acetylation to regulate different biological functions. (B) Model showing how the $\mathrm{N}$-terminal acetylation (red triangles) of transverse filament protein SYP-1 (brown) may be required for $\mathrm{SC}$ assembly. The positions of the $\mathrm{N}$-terminal and C-terminal domains of SYP-1, as demonstrated previously by immuno-electron microscopy (Schild-Prufert et al. 2011), are indicated. Other SYP proteins (SYP-2/3/4) are shown in gray. Highlighted in yellow is the place where the $\mathrm{N}$-terminal domain of SYP-1 may be involved in complex and multidimensional interactions, as supported by its location as well as previously demonstrated interactions for SYP-1 with itself and SYP-2 (Schild-Prufert et al. 2011). 
Our ribosome profiling data also allowed us to explore the possible role of $\mathrm{N}$-terminal acetylation during the translational process. Given that N-terminal acetylation is a cotranslational process and that most of the proteins are efficiently acetylated, the time window for $\mathrm{N}$-terminal acetylation might be extended by translational pausing in case of acetylation deficiency. However, the ribosome profiling data do not support this hypothesis, suggesting that translational elongation is not significantly affected by the $\mathrm{N}$-terminal acetylation machinery.

Interestingly, mapping of a subcellular compartment of the cell revealed an enrichment of $\mathrm{N}$-terminal acetylation in the nucleus and associated structures. This observation suggests that $\mathrm{N}$-terminal acetylation is involved to different extents in different cell compartments. An increase of global $\mathrm{N}$-terminal protein acetylation levels detected for the nuclear fraction suggests that the $\mathrm{N}$-terminally acetylated protein may be more favored than its unacetylated version in forming stable macromolecular structures in the nucleus. Consistent with this, NatB substrates are found to be enriched in the nuclear fraction, and these groups of proteins are highly acetylated. These observations are consistent with the hypothesis that $\mathrm{N}$-terminal acetylation might be widely involved in protein-protein interactions by either directly mediating/enhancing the interactions or affecting the folding of the protein domains. To establish stable structures in the cells, multidimensional interactions might be required, and the $\mathrm{N}$ terminal region/domain of a protein is one of the regions that can be used to mediate an interaction. This is supported by observations that a positive charge at unmodified termini can interfere with $\mathrm{N}$-terminal-mediated protein-protein interactions, while acetylation neutralizes the termini and can mediate hydrophobic interactions (Scott et al. 2011).

More interestingly, by performing peptide profiling, we identified cross-talk between $\mathrm{N}$-terminal acetylation and internal modifications. Whole-worm proteomic analysis applied in this study allowed us to perform peptide profiling along the length of the proteins. This revealed peptide profiles that are altered in an $\mathrm{N}$-terminal region-specific manner (approximately the first 15 amino acids region) in the NatB mutants. Such alterations can only be explained by different modification statuses for protein $\mathrm{N}$-terminal regions between wild type and the NatB mutants, not due to altered protein abundances, as peptide profiles for the remaining regions are not altered (Fig. $3 \mathrm{~A})$. Although our current data do not identify what modifications are preferentially associated with $\mathrm{N}$-terminal acetylation and whether such cross-talk takes place in a cotranslational or post-translational manner, our findings open a novel direction to study the molecular functions and mechanisms regulated via the cross-talk between $\mathrm{N}$-terminal modifications.

\section{Roles of N-terminal acetylation in SC assembly}

The SC is an important structure that promotes crossover formation and accurate chromosome segregation during meiosis. However, the detailed interactions between SC components are still not fully understood. While the role of N-terminal acetylation on other SYP proteins still needs to be determined, our finding that $\mathrm{N}$-terminal acetylation on SYP-1 is critical for SC assembly is particularly interesting. Our previous analysis of the organization of the central region components of the SC in C. elegans showed that the N-terminal domain of SYP-1 is located at the middle of the central region, and its C-terminal domain is located toward the lateral elements (Schild-Prufert et al. 2011). SYP-1 also contains a coiled-coil region in the middle of the protein, which can mediate its dimerization. Such organization of SYP-1 is similar to that of the transverse filament proteins in other organisms, including budding yeast, flies, and mice, where their $\mathrm{N}$-terminal domains were also found to locate at the center of the SC (Liu et al. 1996; Schmekel et al. 1996; Dong and Roeder 2000; Anderson et al. 2005). Moreover, a group of central region proteins has been identified in different organisms (Cahoon and Hawley 2016), suggesting that complex and multiple dimensional interactions might be associated with the N-terminal domain of these transverse filaments. In this study, we show that $\mathrm{N}$-terminal acetylation on SYP-1 is critical for SC assembly and propose that it is likely required for protein-protein interactions in the central region. Further studies are required to explore how $\mathrm{N}$-terminal acetylation of SYP-1 mediates interaction with its binding partners to stabilize the SC structure at the central region.

Interestingly, the N-terminal sequence of SYP-1 is very conserved among Caenorhabditis, including C. elegans, Caenorhabditis remanei, and Caenorhabditis briggsae. We found that conservation for the $\mathrm{N}$-terminal sequence of the transverse filaments is also present in many other organisms, including mammals, flies, bony fish, birds, and yeasts. Moreover, in most of these organisms, the transverse filament proteins are putative NatB substrates (Supplemental Fig. S11). The conservation of N-terminal sequence may suggest its importance in SC assembly across organisms.

Evidence in the literature has shown that the SC is not a static structure and can be constantly remodeled, for example, in response to DSB formation and repair (Couteau and Zetka 2011; Voelkel-Meiman et al. 2012). This remodeling could be highly achievable by modifications at the $\mathrm{N}$ termini of central region components of the SC, as shown in this study.

\section{Materials and methods}

\section{C. elegans genetics}

N2 Bristol was used as the wild-type strain. All worms were cultured at $20^{\circ} \mathrm{C}$ under standard conditions as described in Brenner (1974). The natb-1(fq6) allele was identified through EMS screening for meiotic candidates with univalents at diakinesis. A point mutation (A to $\mathrm{T}$ at position 128 of the cDNA) and a 1-base-pair (bp) insertion 4 bp downstream from the A128T change were identified in the $f q 6$ allele, resulting in a frameshift change. The cra-1 $(f q 2)$ allele used in this study was also identified through EMS screening and carries a 12-bp deletion spanning 
the last $11 \mathrm{bp}$ of intron 10 and the first base pair of exon 11 . The $h t p-3^{D 2 P}$ mutant was generated by CRISPR-Cas9 engineering (Tzur et al. 2013). syp-1 $1^{D 2 P}$ and syp- $1^{\text {wt }}$ transgenic lines were generated by inserting either the mutated syp-1 or wild-type syp-1 genes, respectively, containing the $5^{\prime}$ and $3^{\prime}$ untranslated region sequences of syp-1 in ttTi55605 on chromosome II. The syp-2:: $g f p$ transgenic line was used to perform SYP-2 purification and SYP-2 N-terminal identification by MS. syp-2::gfp transgenic worms show normal meiotic progression and similar brood sizes compared with N2 worms. Moreover, the transgene can fully rescue the syp-2-null mutant, suggesting that SYP-2::GFP is fully functional in C. elegans (Supplemental Fig. S8). The following mutations and chromosome rearrangements were used: LG I: htp-3(rj34); LG III: cra-1(fq2); and LG V: syp-2(ok307), syp-1 (me17), and natb-1(fq6).

\section{Immunofluorescence microscopy}

Immunostaining was performed as in Smolikov et al. (2008). Antibodies were used at the following dilutions: rabbit $\alpha$-SYP-1 (1:200) (MacQueen et al. 2002) and guinea pig a-HTP-3 (1:300) (Goodyer et al. 2008). The following secondary antibodies from Jackson ImmunoResearch Laboratories were used at 1:200 dilution: $\alpha$-rabbit Cy3, $\alpha$-rabbit FITC, $\alpha$-mouse FITC, and $\alpha$-guinea pig FITC. DAPI $\left(1 \mu \mathrm{g} / \mathrm{mL}_{\text {; }}\right.$ Sigma) was used to counterstain DNA. The images presented are either partial or whole projections through three-dimensional data stacks of nuclei. Immunofluorescence images were captured through whole nuclei at 0.2$\mu \mathrm{m}$ intervals with an IX-70 microscope (Olympus) and a cooled CCD camera (CH350, Roper Scientific) under the control of the DeltaVision system with SoftWoRx software (Applied Precision) and were deconvolved using a conservative algorithm with 15 iterations.

\section{MS analysis and identification of $\mathrm{N}$-terminal modifications}

MS analysis was performed as described previously (Zhao et al. 2015). Worm lysates and their tryptic digests were prepared using the filter-aided sample preparation (FASP) procedure (Wisniewski et al. 2009). Peptides from $\sim 40 \mu \mathrm{g}$ of proteins was fractionated into 10 fractions on a strong cation exchange column. Each fraction was analyzed on an Easy-nLC 1000 high-performance liquid chromatograph (Thermo Fisher Scientific) coupled to a Q Exactive mass spectrometer (Thermo Fisher Scientific). Both full-scan and tandem MS (MS/MS) mass spectra were acquired in the Orbitrap in the positive ion mode. ProLuCID (Xu et al. 2015) was used to search the MS/MS spectra against a concatenated forward and reversed C. elegans protein database (WormBase, WS233). ProLuCID was set to search potential modifications (acetylation, phosphorylation, methylation, and ubiquitination as variable modifications) on the first amino acid in each peptide. The estimated false discovery rate (FDR) was no more than $0.2 \%$ for identified spectra and no more than $1.4 \%$ for identified proteins. After identification, peptides corresponding to the protein $\mathrm{N}$ termini were separated from other peptides for further bioinformatic analysis.

For SYP-2 N-terminal identification, nuclei were isolated using a syp-2::gfp transgenic line, and nuclear extracts were used for GFP immunoprecipitation with GFP-Trap agarose beads (ChromoTek).

\section{Protein enrichment analysis}

To analyze protein enrichment in the nuclear fraction compared with the whole-worm lysates, the number of peptides identified for each protein in a sample was first normalized to the total number of peptides identified, followed by a comparison between values for the nuclear fraction and the whole-worm samples. Proteins with at least 10 peptides identified in the nuclear fraction (two technical repeats) were included in the analysis and compared with the values for wholeworm lysates (mean values for three biological replicates). Enrichment index $=$ value for nuclear fraction/value for wholeworm lysates.

\section{Peptide profiling}

Spectra identified by MS for whole-worm lysates were aligned to the C. elegans protein database (WormBase, WS233), and the position of each identified peptide in the reference protein sequence was obtained. Peptides identified for a group of proteins or all proteins were normalized (per 100,000 spectra) and summed to generate peptide profiles. The value for each amino acid position represents the normalized number of identified spectra covering the specific position. For simplicity, proteins with $<80$ amino acids and proteins with multiple isoforms were not included in the analysis.

\section{Ribosomal profiling}

Sychronized worms were cultured on lawns of Escherichia coli OP50 on NGM agar plates and harvested $24 \mathrm{~h}$ after L4 by washing the plates with M9 buffer. Mixtures were transferred to $1.5-\mathrm{mL}$ tubes. Adult worms settled down earlier than eggs and bacteria, allowing the removal of the eggs and bacteria. Clean adult worms were resuspended in lysis buffer $(20 \mathrm{mM}$ Tris at $\mathrm{pH} 8.0,140 \mathrm{mM}$ $\mathrm{KCl}, 5 \mathrm{mM} \mathrm{MgCl}, 100 \mu \mathrm{g} / \mathrm{mL}$ cycloheximide, $0.5 \mathrm{mM} \mathrm{DTT}, 1 \%$ Triton X-100) and flash-frozen drop-wise in liquid nitrogen. Frozen worm pellets were homogenized by cryogrinding with BioSpec cryomill and suspended in ice-cold lysis buffer. Debris was removed by centrifugation, and worm lysates were digested with $1 \mathrm{U} / \mathrm{mL}$ RNase I (Life Technologies) for $1 \mathrm{~h}$ at room temperature. The monosome collection and ribosome footprint library was prepared similarly to Gerashchenko et al. (2012). Briefly, digested lysates were loaded on linear $10 \%-50 \%$ sucrose gradients and centrifuged at 35,000 rpm for $3 \mathrm{~h}$ using a SW-41 Ti rotor. Gradients were fractionated, and the fraction representing the monosome peak was collected. Ribosome-protected mRNA fragments were released with a release buffer $(20 \mathrm{mM}$ Tris $\mathrm{pH} 7.0,2 \mathrm{mM}$ EDTA, $40 \mathrm{U} / \mathrm{mL}$ Superasein [Life Technologies]). Obtained footprints were used to generate sequencing libraries with the ARTseq ribosome profiling kit (Epicentre) according to the manufacturer's instructions.

\section{Bioinformatics analysis}

High-throughput sequencing for ribosome profiling was performed using the Illumina platform. Reads were trimmed of the first nucleotide and the adapter sequence. Resulting reads $>23 \mathrm{nu}-$ cleotides (nt) were used for mapping. In-house Perl scripts were used to prepare reference databases. A total set of predicted/verified coding sequences from the WormBase WS246 release with $18 \mathrm{nt}$ of $5^{\prime}$ and $3^{\prime}$ genomic flanking sequence was used as reference sequences. For transcripts with multiple isoforms, the longest isoform with the earliest start codon was selected. Reads were mapped to the reference data with Bowtie version 1.1.1 (Langmead et al. 2009|. Unique mapped reads were reported with two mismatches allowed. 


\section{Unc worm isolation}

Wild-type moving cra-1 and natb-1 mutants were separated from heterozygous worms carrying Unc-marked balancers and ynchronized $24 \mathrm{~h}$ after L4 young adult worms were washed in M9 buffer. Settled worms were transferred onto the center of an OP50 lawn on a $60-\mathrm{mm}$ dish (200 $\mu \mathrm{L}$ of worms per lawn). Wildtype moving homozygous mutant worms could swim outward and crawl into the OP50 lawn. Unc worms stayed in the liquid at the center and gradually clustered together as the liquid disappeared. Clustered Unc worms were removed with a spatula, and wild-type moving worms were collected by washing the plate with M9.

\section{Nuclear fraction preparation}

Synchronized young adult worms (24 h after L4) were washed three times with M9 buffer. Worms were lysed by vortexing in $15-\mathrm{mL}$ conical tubes containing nuclear isolation buffer $(10 \mathrm{mM}$ HEPES at pH 7.6, $1 \mathrm{mM}$ EGTA, $1.5 \mathrm{mM} \mathrm{MgCl} 2,10 \mathrm{mM} \mathrm{KCl}$, $250 \mathrm{mM}$ sucrose, $0.5 \mathrm{mM}$ DTT, protease inhibitor mixture [Roche]) and small shards of broken glass cover slips. Vortexing was stopped when no intact worm could be observed, while large fragments remained under a dissection scope. Worm debris were removed by centrifugation at $30 \mathrm{~g}$ for $5 \mathrm{~min}$, and supernatants were transferred to $1.5-\mathrm{mL}$ tubes and centrifuged at $30 \mathrm{~g}$ for 3 min to remove residual worm debris. Nuclei in the supernatants were collected by centrifugation at $800 \mathrm{~g}$ for $10 \mathrm{~min}$. Nuclei were then washed twice with nuclear isolation buffer followed by additional centrifugation. To remove soluble components from the nuclear fraction, nuclear isolation buffer containing $0.5 \%$ Triton $\mathrm{X}-100$ was used to suspend the nuclei. The remaining insoluble fraction was then collected by centrifugation. Proteins in this fraction were extracted with $20 \mathrm{mM}$ Tris buffer containing $1 \%$ SDS and further treated for MS analysis as performed for wholeworm lysates.

\section{Acknowledgments}

We thank M. Zetka for the HTP-3 antibody. We are grateful to JoAnne Engebrecht, Luciann Cuenca, and Elisabeth Altendorfer for critical reading of this manuscript; Ian Cheeseman for early discussions about the MS analysis; Monica Pradillo Orellana for help in mapping the natb-1(fq6) mutation; and Itai Yanai for advice on GO term analysis. This work was supported by National Institutes of Health grants R01GM072551 (to M.P.C.) and AG040191 (to V.M.L.), the National Basic Research Program of China (973 Program) number 2014CB849801 (to M.-Q.D.), and a Medical Research Council core funded grant (to E.M.-P.).

\section{References}

Anderson LK, Royer SM, Page SL, McKim KS, Lai A, Lilly MA, Hawley RS. 2005. Juxtaposition of C(2)M and the transverse filament protein C(3)G within the central region of Drosophila synaptonemal complex. Proc Natl Acad Sci 102: 4482-4487.

Arnesen T, Van Damme P, Polevoda B, Helsens K, Evjenth R, Colaert N, Varhaug JE, Vandekerckhove J, Lillehaug JR, Sherman F, et al. 2009. Proteomics analyses reveal the evolutionary conservation and divergence of $\mathrm{N}$-terminal acetyltransferases from yeast and humans. Proc Natl Acad Sci 106: $8157-8162$.

Arnesen T, Starheim KK, Van Damme P, Evjenth R, Dinh H, Betts MJ, Ryningen A, Vandekerckhove J, Gevaert K, Anderson D.
2010. The chaperone-like protein HYPK acts together with NatA in cotranslational N-terminal acetylation and prevention of Huntingtin aggregation. Mol Cell Biol 30: 1898-1909.

Brenner S. 1974. The genetics of Caenorhabditis elegans. Genetics 77: 71-94.

Cahoon CK, Hawley RS. 2016. Regulating the construction and demolition of the synaptonemal complex. Nat Struct Mol Biol 23: 369-377.

Chan RC, Chan A, Jeon M, Wu TF, Pasqualone D, Rougvie AE, Meyer BJ. 2003. Chromosome cohesion is regulated by a clock gene paralogue TIM-1. Nature 423: 1002-1009.

Couteau F, Zetka M. 2011. DNA damage during meiosis induces chromatin remodeling and synaptonemal complex disassembly. Dev Cell 20: 353-363.

Dong H, Roeder GS. 2000. Organization of the yeast Zip1 protein within the central region of the synaptonemal complex. J Cell Biol 148: 417-426.

Esmailpour T, Riazifar H, Liu L, Donkervoort S, Huang VH, Madaan S, Shoucri BM, Busch A, Wu J, Towbin A, et al. 2014. A splice donor mutation in NAA10 results in the dysregulation of the retinoic acid signalling pathway and causes Lenz microphthalmia syndrome. J Med Genet 51: 185-196.

Gautschi M, Just S, Mun A, Ross S, Rucknagel P, Dubaquie Y, Ehrenhofer-Murray A, Rospert S. 2003. The yeast Na-acetyltransferase NatA is quantitatively anchored to the ribosome and interacts with nascent polypeptides. Mol Cell Biol 23: 7403-7414.

Gerashchenko MV, Lobanov AV, Gladyshev VN. 2012. Genomewide ribosome profiling reveals complex translational regulation in response to oxidative stress. Proc Natl Acad Sci 109: 17394-17399.

Goetze S, Qeli E, Mosimann C, Staes A, Gerrits B, Roschitzki B, Mohanty S, Niederer EM, Laczko E, Timmerman E, et al. 2009. Identification and functional characterization of N-terminally acetylated proteins in Drosophila melanogaster. PLoS Biol 7: e1000236.

Goodyer W, Kaitna S, Couteau F, Ward JD, Boulton SJ, Zetka M. 2008. HTP-3 links DSB formation with homolog pairing and crossing over during C. elegans meiosis. Dev Cell 14: 263-274.

Hassold T, Hall H, Hunt P. 2007. The origin of human aneuploidy: where we have been, where we are going. Hum Mol Genet 16: R203-R208.

Helbig AO, Rosati S, Pijnappel PW, van Breukelen B, Timmers MH, Mohammed S, Slijper M, Heck AJ. 2010. Perturbation of the yeast $\mathrm{N}$-acetyltransferase NatB induces elevation of protein phosphorylation levels. BMC Genomics 11: 685.

Holmes WM, Mannakee BK, Gutenkunst RN, Serio TR. 2014. Loss of amino-terminal acetylation suppresses a prion phenotype by modulating global protein folding. Nat Commun 5: 4383.

Hwang CS, Shemorry A, Varshavsky A. 2010. N-terminal acetylation of cellular proteins creates specific degradation signals. Science 327: 973-977.

Ingolia NT, Brar GA, Rouskin S, McGeachy AM, Weissman JS. 2012. The ribosome profiling strategy for monitoring translation in vivo by deep sequencing of ribosome-protected mRNA fragments. Nat Protoc 7: 1534-1550.

Kalvik TV, Arnesen T. 2013. Protein N-terminal acetyltransferases in cancer. Oncogene 32: 269-276.

Kim HK, Kim RR, Oh JH, Cho H, Varshavsky A, Hwang CS. 2014. The N-terminal methionine of cellular proteins as a degradation signal. Cell 156: 158-169.

Langmead B, Trapnell C, Pop M, Salzberg SL. 2009. Ultrafast and memory-efficient alignment of short DNA sequences to the human genome. Genome Biol 10: R25. 
Liu JG, Yuan L, Brundell E, Bjorkroth B, Daneholt B, Hoog C. 1996. Localization of the N-terminus of SCP1 to the central element of the synaptonemal complex and evidence for direct interactions between the $\mathrm{N}$-termini of SCP1 molecules organized head-to-head. Exp Cell Res 226: 11-19.

MacQueen AJ, Colaiacovo MP, McDonald K, Villeneuve AM. 2002. Synapsis-dependent and -independent mechanisms stabilize homolog pairing during meiotic prophase in C. elegans. Genes Dev 16: 2428-2442.

Michalski A, Damoc E, Hauschild JP, Lange O, Wieghaus A, Makarov A, Nagaraj N, Cox J, Mann M, Horning S. 2011. Mass spectrometry-based proteomics using $\mathrm{Q}$ Exactive, a high-performance benchtop quadrupole Orbitrap mass spectrometer. Mol Cell Proteomics 10: M111.011015.

Myklebust LM, Van Damme P, Stove SI, Dorfel MJ, Abboud A, Kalvik TV, Grauffel C, Jonckheere V, Wu Y, Swensen J, et al. 2015. Biochemical and cellular analysis of Ogden syndrome reveals downstream Nt-acetylation defects. Hum Mol Genet 24: 1956-1976.

Norris AD, Kim HM, Colaiacovo MP, Calarco JA. 2015. Efficient genome editing in Caenorhabditis elegans with a toolkit of dual-marker selection cassettes. Genetics 201: 449-458.

Page SL, Hawley RS. 2004. The genetics and molecular biology of the synaptonemal complex. Annu Rev Cell Dev Biol 20: 525-558.

Polevoda B, Norbeck J, Takakura H, Blomberg A, Sherman F. 1999. Identification and specificities of N-terminal acetyltransferases from Saccharomyces cerevisiae. EMBO I 18: 6155-6168.

Popp B, Stove SI, Endele S, Myklebust LM, Hoyer J, Sticht H, Azzarello-Burri S, Rauch A, Arnesen T, Reis A. 2015. De novo missense mutations in the NAA10 gene cause severe non-syndromic developmental delay in males and females. Eur I Hum Genet 23: 602-609.

Rog O, Dernburg AF. 2015. Direct visualization reveals kinetics of meiotic chromosome synapsis. Cell Rep 10: 1639-1645.

Rope AF, Wang K, Evjenth R, Xing J, Johnston JJ, Swensen JJ, Johnson WE, Moore B, Huff CD, Bird LM, et al. 2011. Using VAAST to identify an X-linked disorder resulting in lethality in male infants due to N-terminal acetyltransferase deficiency. Am J Hum Genet 89: 28-43.

Schild-Prufert K, Saito TT, Smolikov S, Gu Y, Hincapie M, Hill DE, Vidal M, McDonald K, Colaiacovo MP. 2011. Organization of the synaptonemal complex during meiosis in Caenorhabditis elegans. Genetics 189: 411-421.

Schmekel K, Meuwissen RL, Dietrich AJ, Vink AC, van Marle J, van Veen H, Heyting C. 1996. Organization of SCP1 protein molecules within synaptonemal complexes of the rat. Exp Cell Res 226: 20-30.

Scott DC, Monda JK, Bennett EJ, Harper JW, Schulman BA. 2011. N-terminal acetylation acts as an avidity enhancer within an interconnected multiprotein complex. Science 334: 674-678.

Setty SR, Strochlic TI, Tong AH, Boone C, Burd CG. 2004. Golgi targeting of ARF-like GTPase Arl3p requires its $\mathrm{Na}$-acetylation and the integral membrane protein Sys1p. Nat Cell Biol 6: 414-419.

Severson AF, Ling L, van Zuylen V, Meyer BJ. 2009. The axial element protein HTP-3 promotes cohesin loading and meiotic axis assembly in C. elegans to implement the meiotic program of chromosome segregation. Genes Dev 23: 1763-1778.
Shemorry A, Hwang CS, Varshavsky A. 2013. Control of protein quality and stoichiometries by N-terminal acetylation and the N-end rule pathway. Mol Cell 50: 540-551.

Smolikov S, Eizinger A, Schild-Prufert K, Hurlburt A, McDonald K, Engebrecht J, Villeneuve AM, Colaiacovo MP. 2007. SYP-3 restricts synaptonemal complex assembly to bridge paired chromosome axes during meiosis in Caenorhabditis elegans. Genetics 176: 2015-2025.

Smolikov S, Schild-Prufert K, Colaiacovo MP. 2008. CRA-1 uncovers a double-strand break-dependent pathway promoting the assembly of central region proteins on chromosome axes during C. elegans meiosis. PLoS Genet 4: e1000088.

Smolikov S, Schild-Prufert K, Colaiacovo MP. 2009. A yeast twohybrid screen for SYP-3 interactors identifies SYP-4, a component required for synaptonemal complex assembly and chiasma formation in Caenorhabditis elegans meiosis. PLoS Genet 5: e1000669.

Starheim KK, Gevaert K, Arnesen T. 2012. Protein N-terminal acetyltransferases: when the start matters. Trends Biochem Sci 37: 152-161.

Tzur YB, Friedland AE, Nadarajan S, Church GM, Calarco JA, Colaiacovo MP. 2013. Heritable custom genomic modifications in Caenorhabditis elegans via a CRISPR-Cas9 system. Genetics 195: 1181-1185.

Urbancikova M, Hitchcock-DeGregori SE. 1994. Requirement of amino-terminal modification for striated muscle alpha-tropomyosin function. J Biol Chem 269: 24310-24315.

Van Damme P, Hole K, Pimenta-Marques A, Helsens K, Vandekerckhove J, Martinho RG, Gevaert K, Arnesen T. 2011. NatF contributes to an evolutionary shift in protein $\mathrm{N}$-terminal acetylation and is important for normal chromosome segregation. PLoS Genet 7: e1002169.

Van Damme P, Lasa M, Polevoda B, Gazquez C, Elosegui-Artola A, Kim DS, De Juan-Pardo E, Demeyer K, Hole K, Larrea E, et al. 2012. N-terminal acetylome analyses and functional insights of the N-terminal acetyltransferase NatB. Proc Natl Acad Sci 109: 12449-12454.

Van Damme P, Gawron D, Van Criekinge W, Menschaert G. 2014. N-terminal proteomics and ribosome profiling provide a comprehensive view of the alternative translation initiation landscape in mice and men. Mol Cell Proteomics 13: 1245-1261.

Voelkel-Meiman K, Moustafa SS, Lefrancois P, Villeneuve AM, MacQueen AJ. 2012. Full-length synaptonemal complex grows continuously during meiotic prophase in budding yeast. PLoS Genet 8: e1002993.

Wisniewski JR, Zougman A, Nagaraj N, Mann M. 2009. Universal sample preparation method for proteome analysis. Nat Methods 6: 359-362.

Xu T, Park SK, Venable JD, Wohlschlegel JA, Diedrich JK, Cociorva D, Lu B, Liao L, Hewel J, Han X, et al. 2015. ProLuCID: an improved SEQUEST-like algorithm with enhanced sensitivity and specificity. J Proteomics 129: 16-24.

Zhao HQ, Zhang P, Gao H, He X, Dou Y, Huang AY, Liu XM, Ye AY, Dong MQ, Wei L. 2015. Profiling the RNA editomes of wild-type C. elegans and ADAR mutants. Genome Res 25: 66-75.

Zickler D, Kleckner N. 2015. Recombination, pairing, and synapsis of homologs during meiosis. Cold Spring Harb Perspect Biol 7: a016626. 


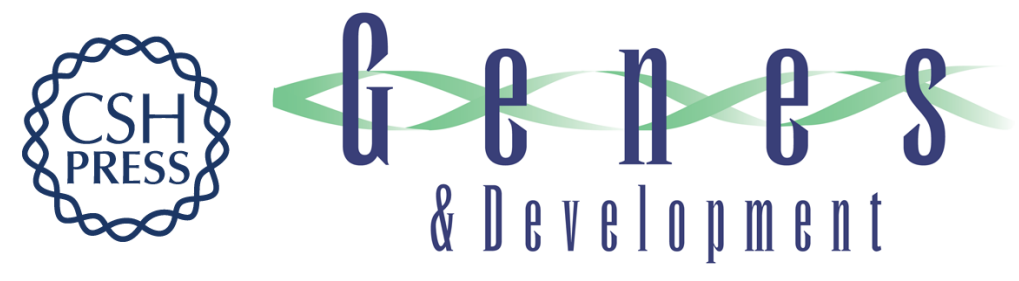

\section{$\mathrm{N}$-terminal acetylation promotes synaptonemal complex assembly in C. elegans}

Jinmin Gao, Consuelo Barroso, Pan Zhang, et al.

Genes Dev. 2016, 30: originally published online November 14, 2016

Access the most recent version at doi:10.1101/gad.277350.116

\section{Supplemental http://genesdev.cshlp.org/content/suppl/2016/11/14/gad.277350.116.DC1 Material}

References This article cites 51 articles, 23 of which can be accessed free at: http://genesdev.cshlp.org/content/30/21/2404.full.html\#ref-list-1

Creative This article is distributed exclusively by Cold Spring Harbor Laboratory Press for the first Commons six months after the full-issue publication date (see

License http://genesdev.cshlp.org/site/misc/terms.xhtml). After six months, it is available under a Creative Commons License (Attribution-NonCommercial 4.0 International), as described at http://creativecommons.org/licenses/by-nc/4.0/.

Email Alerting Receive free email alerts when new articles cite this article - sign up in the box at the top Service right corner of the article or click here.

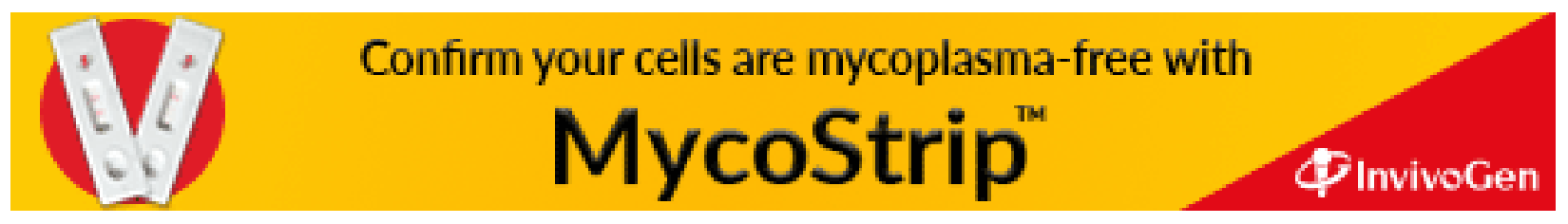

